\title{
Políticas de informação, as tecnologias de informação e comunicação e a participação no âmbito da sociedade da informação: enfoque na inclusão digital do global ao local
}

\author{
Information policy, information technology and communication \\ and participation in the information society: focus on digital \\ inclusion from global to local sphere
}

Barbara Coelho NEVES

\section{RESUMO}

Trata-se de um artigo que procura discutir, à luz da literatura sobre políticas públicas e política de informação, a questão da sociedade da informação. Tem como objeto de análise a Sociedade da Informação enquanto ação política, no contexto global, regional, nacional e local. $\bigcirc$ foco é a participação por meio da inclusão digital. A metodologia utilizada contou com a observação de sítios institucionais, de notícia e a literatura do campo. Esta análise também apresenta algumas definições sobre o tema políticas públicas, atores políticos, novos agentes e instrumentos envolvidos na agenda global da sociedade da informação.

Palavras-chave: Políticas públicas. Políticas de informação. Sociedade da informação. Participação. Inclusão digital.

\section{A B S T R A C T}

This article presents the discussion about the information society context subjected to scientific literature on public policies and information policy. Its object of analyses is the Information Society viewed as a policy action in global, regional, national and local context levels. The emphasis is on digital inclusion as a participation instrument. Employed methodology accomplished observation of institutional, journalistic and specific scientific literature sites. This analysis also presents some definitions about public policies issues, new political actors and instruments involved in the global agenda of the information society.

Keywords: Public policies. Information policy. Information society. Participation. Digital inclusion.

\footnotetext{
1 Professora. Universidade Federal da Bahia, Instituto de Humanidades, Artes e Ciências. Prof. Milton Santos. Reitor Miguel Calmon, s/n., Canela, 40110-903, Salvador, BA, Brasil. E-mail: <barbaran@ufba.br>.

Recebido em 21/1/2010 e aceito para publicação em 5/4/2010.
} 
I NTRODUÇÃ O

A Deusa tecnologia não fala espanhol [...](Galeano, 1978)

[...nem português de brasileiro e africano].

Muitas foram as transformações que aconteceram no mundo, em finais do milênio, impactando em mudanças nas relações sociais, no espaço e, dentre tantos outros aspectos, nos fluxos de informação. Tais transformações, somadas, geraram modificações, ao longo desse período, das políticas que as regem, que impactaram de diferentes formas na América Latina e, em seu território, apresentaram características com elementos ora homogêneos, ora heterogêneos.

O controle estatal intensificado no México, Brasil e Argentina, a partir de 1930 até o final dos anos 1970, constituiu uma característica das economias latinoamericanas. Sucessivos golpes de Estado postergaram o impulso científico e desenvolvimentista em tecnologias não copiadas de universidades e centros culturais mais avançados (Galeano, 1978). Galeano (1978) demonstrou que o atraso quanto à produção de conhecimentos especiais (know-how) condicionou que a maioria das transferências de tecnologias, desenvolvida entre os países da região e os Estados Unidos e Europa, constituísse troca de técnicas de domínio público como se fossem de conhecimento especializado. A diminuição da abertura para os investimentos externos contribuiu para a dívida externa da região (Boeker, 1995).

No Brasil, a expressão política pública começa a ser discutida a partir da década de 1970, substituindo, de certa forma, o espaço antes ocupado pela expressão "planejamento estatal" (Ferreira, 2006). Ao final da década de 1970, há um fortalecimento do ator Estado sobre as instituições e a sociedade civil. Na década de 1980, uma nova geração de políticos chega ao poder - Menen na Argentina, Salinas no México, dentre outros - e assim há uma revisão da estratégia econômica e das políticas de informação e comunicação, conferindo novos rumos às relações sociais e entre Estado e sociedade (Boeker, 1995; Sorj; Martuccelli, 2008). comunicação unificam os espaços de comunicação". (Sori; Martuccelli, 2008). Rádio e TV têm um papel expansionista, mas vertical, na América Latina, em consonância com a política "de um para todos", comum naquele momento.

Na América Latina e, especificamente, no Brasil, a participação dos cidadãos vem sendo construída como um dos princípios organizativos centrais, declarado e repetido em foros regionais e internacionais, dos processos de deliberação democrática, sobretudo no âmbito local (Milani, 2006). No cerne da Democracia Deliberativa desses países, brotam políticas públicas direcionadas às variadas questões que buscam estabelecer os mais amplos e diretos mecanismos de participação dos indivíduos (Sanchez, 2006).

A participação dos cidadãos - também conhecida como participação social, participação popular, participação democrática, participação comunitária, entre os muitos termos atualmente utilizados para referir-se à prática de inclusão dos cidadãos e das Organizações da Sociedade Civil (OSC) no processo decisório (Milani, 2006), tem sido preocupação das políticas públicas. A participação, quando pensada no âmbito da universalização da informação, é denominada de política de informação.

O Programa Sociedade da Informação, uma ação formulada por políticas governamentais e organizacionais voltadas à informação, é destinado à inclusão digital e de infraestrutura para disseminação de informação e conteúdos digitais. Como pré-requisito para implementação dessa Sociedade, a participação do cidadão é essencial, "[...] motivada pela expansão do efeito multiplicador da produção da informação, pela tomada de decisões autônomas em grupo e por evitar-se a tendência a uma sociedade administrativamente centralizada" (Marciano, 2006, p.43). A difusão social das Tecnologias de Informação e Comunicação (TIC) é uma preocupação que vem-se intensificando ao longo dos anos. Embora, com todo "ceticismo e as múltiplas críticas enfrentadas há mais de uma década, atualmente se aceita que as TIC estão produzindo uma profunda revolução tecnológica, comparável às suscitadas pela escrita, a imprensa ou a industrialização" (Echeverría, 2008, p.172). Tal evolução tem gerado nos países comoções várias, como a produção de planos, metodologias e projetos, procurando seguir as linhas de ações propostas pelos macros organismos, a exemplo da ONU. 
Tendo em vista a inserção dos indivíduos no contexto da sociedade da informação, surge a formulação de instrumentos das políticas públicas ligadas à democratização da informação, a exemplo do governo eletrônico e da inclusão digital.

Este estudo visou a uma análise do Programa Sociedade da Informação, focando o polêmico e popular mecanismo de políticas públicas ligadas à informação - a inclusão digital. Para entendimento e análise desse fenômeno, observou-se o Programa no contexto global (mundo), regional (América Latina), nacional (Brasil) e um exemplo do local (Bahia), procurando fazer uma contextualização histórica, desde sua implementação aos dias atuais.

A metodologia de análise baseou-se nas informações disponibilizadas em sítios, observatórios e mapeamentos relacionados ao Programa; e nas notícias veiculadas no respectivo período, procurando convergir com a literatura produzida de cunho governamental e científico.

\section{POLÍTICAS PÚBLICAS E DE INFORMAÇÃO NO CONTEXTO DO ESTADO GLOBALIZADO}

Há três premissas a serem consideradas: a aldeia global vs. ideia de local - de um lado o fluxo da informação dominante, determinando as identidades locais, do outro, um fluxo dinâmico entre o global e o local, interferindo um no outro, gerando identidades múltiplas; a nova ordem interfere nas políticas de informação e na dificuldade de dominar o fluxo de informação por parte do Estado. Observa-se que o contexto de globalização converge com as interferências do Estado na sociedade.

Antes de adentrar nas questões de mundialização e tecnologia - que culminaram no desenho atual de interação política entre Estado, fluxo de informação e sociedade -, faz-se adequado evocar algumas definiçõoes acerca do termo políticas públicas.

As principais formas de o Estado atual, em crise de governança e governabilidade, intervir na sociedade são por meio da legislação e de políticas públicas, tratando-se a primeira de ordem decisória política e a segunda de uma política de característica pública. De acordo com Rua e Carvalho (1998, p.1, grifo dos autores), as "[...] políticas públicas (policies), por sua vez, são outputs, resultantes da atividade política (politics): compreendem o conjunto das decisões e ações relativas à alocação imperativa de valores." As políticas públicas são o resultado de transações entre atores políticos (Marciano, 2006). Tais políticas são o inverso do controle democrático (Milani, 2006). Assim, entendem-se políticas públicas como o resultado de um debate sobre determinada problemática entre Estado e sociedade, levada a cabo por jogos que envolvem poder na arena do Estado. Elas possuem caráter público, sendo possuidoras de autoridade soberana do poder do Estado, implicando "[...] procedimentos formais e informais de resolução pacífica de conflitos". (Rua; Carvalho, 1998). A possibilidade mais concreta de solução do conflito certamente está na radicalização da democracia e do exercício da cidadania (Jambeiro, 2008). Os envolvidos nesses conflitos são chamados de atores.

Os atores políticos são variados, podendo ser públicos ou privados. Os públicos são aqueles que se distinguem por exercer funções públicas e por mobilizar os recursos associados a essas funções. São categoria de atores públicos os políticos e os burocratas. Quanto aos atores privados, destacam-se os empresários, os trabalhadores e as $\mathrm{ONG}$, podendo atuar de forma isolada ou coletiva. Possuem força suficiente para interferirem na economia, mas os trabalhadores, somente quando de forma organizada (Rua; Carvalho, 1998).

Os agentes internacionais (Fundo Monetário Internacional - FMI, Banco Mundial, Organização das Nações Unidas para a/educação, a Ciência e a Cultura - UNESCO) possuem o poder de influenciar com notoriedade na política e economia dos países. Podem ser organizações ou governos de países com os quais se mantêm relações de troca importante (Rua; Carvalho, 1998). Outro ator de relevância no contexto atual é a mídia que, embora não atue diretamente, exerce poder como formadora de opinião e motivadora de ações dos outros atores para o conflito. Segundo Santos (2002), o consumo de massa atual valeu-se da mídia, que cresce verticalmente em países como o Brasil, impondo gostos e preços e produzindo uma massa mais voltada a preocupações que garantam "[...] não propriamente o indivíduo tornado cidadão, mas o indivíduo tornado consumidor" (Santos, 2002, p. 15). Voltando-se para o Estado, a ele implica atuar como "ator e arena política do poder decisório" (Milani, 2006).

O novo cenário cultural e econômico imposto pelo processo de globalização, a "crise do Estado e a 
consequente necessidade de reforma da administração pública são o reflexo de um paradoxo gerado pela combinação entre democracia e mercado" (Milani, 2006). Dentre esse e outros aspectos, visar à inserção de indivíduos em um contexto a cada dia mais acirrado pela competência informacional é um desafio. Esse é um ponto que se mostra ainda mais vultoso à luz de grandes deficiências e problemas que, historicamente, se avolumaram rumo à situação vivenciada contemporaneamente e que se contrapõe à inclusão digital (Marciano, 2006).

Por esse caminho, a forma e a fisionomia socioeconômica e cultural dos países poderão ser alteradas pela inclusão contínua de novos estratos sociais nos processos decisórios nacionais e internacionais (Jambeiro, 2008).

Longe de ser um fenômeno novo, a globalização é um conjunto de processos sustentado pelas grandes evoluções tecnológicas (informática e comunicações), pelo aprofundamento da integração econômica, social, política e cultural, eliminação do espaço/tempo e máxima mobilidade àqueles que formam a elite global, implicando o progresso de alguns e a desventura de muitos. São suas palavras-chave o êxito, a abundancia e a inclusão associados, respectivamente, à especulação, ao empobrecimento e à exclusão do universo de possibilidades proporcionadas pelo seu alicerce tecnológico (Santos, 2002; Bueno Sanchéz, 2008). Contrariamente a ser um processo homogêneo, tem comentado Bueno Sanchéz (2008, tradução livre) que "se trata na verdade de um desenvolvimento desigual em seus diferentes níveis e dimensões".

Essa nova mudança de ordem, que implica o posicionamento dos atores para lidar com a informação, é a suposta modernidade líquida, onde se solta o freio da "[...] regulamentação, da liberalização, da flexibilização, da 'fluidez' crescente, do descontrole dos mercados financeiros, imobiliário e de trabalho [...]" visando à construção de uma "[...] ordem nova e melhor para substituir a velha ordem defeituosa [...] da modernidade sólida, pesada, industrial" (Bauman, 2001, p. 11).

Segundo Bauman (2001), a modernidade líquida é fluída, contemporânea e de características nômades - seja para sujeitos ou capital - e em forma de rede, contrapondo ao fordismo sólido, condensado e de formas sistêmicas. A apresentação dos membros como indivíduos é a marca registrada da sociedade moderna.

Para Bauman (2001, p. 16), a "[...] velocidade do movimento e o acesso a meios mais rápidos de mobilidade chegaram aos tempos modernos à posição de principal ferramenta do poder e da dominação". Nesse estágio fluído da modernidade, as grandes massas, ainda presas ao princípio da territorialidade por questões sócio/econômicas/informacionais ou por serem evitadas pelas economias desenvolvidas - são uma maioria assentada e "[...] dominada pela elite nômade e extraterritorial" (Bauman, 2001, p.20). Como também explica Santos (2002, p.91), “[...] estar na periferia significa dispor de menos meios efetivos para atingir as fontes e os agentes do poder, dos quais se está mal ou insuficiente informado". A distribuição desigual da informação está, segundo Milton Santos, atrelada ao posicionamento geográfico que tem suas distâncias e diferenças duplicadas pela política vigente.

Estado tem dificuldade de controlar o fluxo de informação e emitir um retorno com a dinâmica que requer o novo padrão imerso nas novas políticas de informação que induzem e são induzidas pelo poder invisível. Por outro lado, "[...] o que o novel Príncipe pode vir a saber dos próprios sujeitos é incomparavelmente superior ao que podia saber de seus súditos, mesmo o monarca mais absoluto do passado" (Bobbio, 2009, p.31). Essa afirmativa, que corrobora com o texto de Sanchez (2006), pode ser percebida em todo modelo que implica controle da informação, seja no âmbito do Estado, como o governo eletrônico, seja no lado comercial, como o Google, por exemplo, que colhe todas as informações enviadas ou recebidas por seus usuários seja por meio de suas ferramentas de e-mail, de bate-papo ou em sua busca genérica com o intuito de formar uma rede que antecipa qualquer demanda informacional que, por ventura, o indivíduo possa ter.

Os atores internacionais "[...] atuam em escala global, concentrando atomizadamente vastas parcelas de poder [...] (Rua; Carvalho, 1998, p.4). Em 1990, um norte americano ganhava, em média, 38 vezes mais que um trabalhador da Tanzânia. Com a intensificação dos mecanismos de globalização, na contemporaneidade, essa diferença se alargou, implicando uma concentração de 61 vezes mais para esses americanos. Nunca houve um desnível tão grande entre um pequeno grupo de países e a maioria esmagadora dos países da humanidade (Santos, 2004). 
poder navega para longe das bases reais, para além do alcance e do controle dos indivíduos, mergulhando na "[...] extraterritorialidade das redes eletrônicas" (Bauman, 2001, p.50). Seus princípios como coloca o autor - são fuga, evitação e descompromisso de qualquer ordem, seja econômica ou social, tendo como condição ideal a invisibilidade.

Dessa forma, é no quesito social que a globalização tem mostrado sua face mais danosa, por não privilegiar o crescimento balanceado. A globalização foi imposta pelos países centrais aos países semiperiféricos e periféricos, desta maneira aumentando cada vez mais a desigualdade social, porque o modelo visa beneficiar os países ricos, onde a economia nunca é evitada. Tratando-se de globalização, as contradições são muitas, como: desigualdade social mundial, distribuição desigual da informação e, ao mesmo tempo, aumento dos gastos sociais em esfera global. Exemplo disso é o Programa Sociedade da Informação, que visa à instituição do debate e do elenco de iniciativas para inserção de sujeitos no novo conjunto de condições e circunstâncias que emergem do entrelaçamento entre a nova ordem e o dinamismo das tecnologias de informação e comunicação. Para promoção dessa contestação, o processo que envolve a busca, coleta, armazenagem, disseminação e descarte de informação passa a ser considerado como um bem de valor agregado para pessoas, instituições e países no contexto vigente. Um conjunto de políticas voltadas à pesquisa, aos acervos, ao desenvolvimento de tecnologias e à infraestrutura, assim como acesso mais universalizado a elas, formam a política de informação. Na sua definição, segundo Marciano (2006) trata-se de "uma política voltada à caracterização, ao delineamento e a definição de ações voltadas à utilização da informação como elemento transformador da sociedade nas esferas governamentais, organizacionais e privadas".

Assim, faz-se condizente analisar o desenrolar do Programa Sociedade da Informação no âmbito do Estado e sociedade com o foco na inclusão digital, a partir de sua implementação como política de informação.

\section{A SOCIEDADE DA INFORMAÇÃO NO CONTEXTO GLOBAL, REGIONAL, NACIONAL E LOCAL}

A longo prazo, a informatização será "para o bem ou para o mal" um ingrediente fundamental do
"[...] equilíbrio da autoridade que representa o Estado e a liberdade da sociedade" (Felicié Soto, 2008, p.20, tradução nossa). Nesse novo modelo de sociedade onde a convergência da informática, comunicação e informação cooperam ou desfiguram a sustentação da democracia no mundo, surge a ideia de sociedade da informação.

De acordo com a Cúpula Mundial sobre a Sociedade da Informação (2009), a sociedade da informação é um conceito em evolução que vem alcançando variados níveis em todo o mundo, consoantes as diferentes etapas de desenvolvimento de cada país.

Para visualizar a evolução dos interesses acerca da sociedade da informação faz-se necessário uma breve contextualização histórica no âmbito global, regional, nacional e local, visando contextualizar como as esferas dialogam, principalmente, no tocante das questões ligadas à inclusão digital.

Contextualização histórica da sociedade da informação: mundo, América Latina, Brasil e Bahia

Ainda nas primeiras reuniões de construção da Cúpula Mundial sobre a Sociedade da Informação (CMSI), a infoexclusão já instituía uma preocupação, embora naquele momento a atenção estivesse mais dirigida à distribuição da infraestrutura.

A contextualização, a partir de uma visão do global para o local, considerando suas principais propostas e iniciativas, constitui-se como pertinente para o entendimento do desdobramento das políticas de informação focadas na viabilização de infraestrutura por parte do principal ator público, sobretudo na América Latina, o Estado.

\section{Mundo}

No mundo o debate da inclusão digital deu-se com a interlocução de diversos atores, tendo a discussão origem, inicialmente, na esfera pública encabeçada pelo Estado, organismos internacionais e as organizações governamentais (ONG). Esses organismos representaram um papel relevante na promoção de agendas e fóruns de discussão entre Estado e sociedade no momento de implantação da Sociedade da Informação.

Atores de destaque global, organizações internacionais como a Organização das Nações Unidas 
(ONU) e a União Internacional de Telecomunicações (UIT), foram protagonistas na formação de políticas de informação no contexto mundial. Muitos países e organizações reuniram grupos com o intuito de estabelecerem iniciativas, visando desenvolver estratégias e políticas para fins de acompanhar e resolver as demandas, atreladas às diferenças inerentes à sociedade da informação. Algumas dessas iniciativas precedentes são:

A National Information Infrastructure the Clinton and Gore, fundada em 1993, tendo como principal proposta o desenvolvimento de novas tecnologias de informação e comunicação (TIC) e vias para trânsito da informação, visando à melhoria da economia e qualidade de vida americana.

Na Europa, a iniciativa Una Sociedad de la Información para Todos, assegurada pela Comissão Européia, em 1996, visava acelerar a implementação de TIC e proporcionar aos europeus "conhecimento" necessário para que pudessem utilizá-las em benefício próprio.

O Cumbre Mundial Sobre la Sociedad de la Información (CMSI) ou Cúpula Mundial sobre a Sociedade da Informação (tradução) foi o primeiro espaço exclusivamente dedicado à formação e discussão de políticas para a sociedade da informação, sendo celebrada pela UIT e aprovada em 21 de dezembro de 2001 pelas Nações Unidas.

Em 1998, começam conjecturas sediadas no âmbito da UIT, visando à criação de um programa mundial para a sociedade da informação. Em 2001 a União cria a CMSI com a proposta de trabalhar com metas, princípios e planos de ação que seriam amplamente discutidos em dois grandes fóruns denominados de Fase 1 em Genebra e Fase 2 em Túnis. (Cumbre..., 2009).

As principais demandas que impulsionam o Programa Sociedade da Informação no contexto mundial compreendem a revolução digital, a exclusão digital e a necessidade de discutir uma agenda em escala mundial.

A primeira causa tratou da revolução digital impulsionada pelo ronco dos motores das tecnologias de informação e comunicação (TIC), as quais nortearam mudanças nas formas de pensar, relacionar e ganhar o sustento (empregabilidade). A criação de novas formas de criar e acumular conhecimento, educar, aprender e transmitir informação foram profundamente mexidas com a inserção daquelas novas tecnologias. E, gradualmente, a maneira pela qual os países faziam negócios e regiam suas economias foi reestruturada, implicando transformações que alcançaram a esfera de sua governança, comprometimento político e social. Também nesse contexto, emergiram questões humanitárias, como ecologia e meio ambiente. As formas de relacionamento, de país para país, de pessoa para pessoa, passaram a contar com aparatos de comunicação, alterando a noção de tempo e espaço, criando novas formas de entretenimento e culturas, as quais foram prerrogativas para os grandes organismos internacionais levarem em consideração que $\mathrm{o}$ acesso à informação é requisito prévio para alcançar os Objetivos do Milênio, projetando melhorar a vida de milhões de pessoas em todo o mundo (Cumbre..., 2009).

A segunda causa trata de que, enquanto a revolução digital ampliava o horizonte da aldeia global, paradoxalmente, grande parcela da população mundial não estava sendo incluída nesse processo. Tal fenômeno de poder precisava ser observado com cautela, já que, para se usufruir da revolução, era necessário se ter, no mínimo, acesso a tais tecnologias. A não participação, ou sua precariedade, na revolução digital compreende no aumento da brecha que coloca em duas pontas distantes conhecimento e ignorância; riqueza e pobreza "mórbida" dentro dos países e entre eles. Assim, essas organizações mundiais consideraram como imperativo que o mundo lutasse contra a exclusão digital, desenvolvendo mecanismos que proporcionassem ampla e rápida disponibilização de estruturas e aparatos tecnológicos.

$\mathrm{Na}$ terceira causa, os organismos mundiais observaram a necessidade permanente de discutir uma agenda em escala internacional. Esses debates promoveriam mais debates que, representados pelos grandes fóruns de discussão - a exemplo da primeira fase da CMSI em dezembro de 2003 em Genebra e a segunda fase em novembro de 2005 em Túnis - têm como norteadores as temáticas em torno da intensificação da exclusão social promovida pela ausência de acesso à revolução digital. Echeverría (2008) analisou o argumento da CMSI da seguinte forma: primeiro, convém deter-se em que, atualmente, se trata de desenvolver novas capacidades tanto para as pessoas, como para as instituições e segundo, os sistemas educativos precisam incluir entre seus objetivos 
a aquisição dessas "capacidades TIC", que são várias e diversas. E acrescenta que o desenvolvimento de tais capacidades não pode ser produzido somente no campo individual, mas também em nível institucional e coletivo (Echeverría, 2008, p. 173), ou seja, no plano das políticas públicas.

Atualmente a CMSI continua com a tutela das Nações Unidas e UIT, possui 191 países membros e desenvolve uma política focada em proporcionar estruturas baseadas em TIC para o desenvolvimento. Sua atual proposta, de acordo com a última declaração (Túnis), visa à busca de respostas eficazes para construir uma sociedade da informação calcada em metas (Cumbre..., 2006). No compromisso firmado em Túnis, a CMSI estende o convite às empresas, governo e setor privado, visando que tais eixos passem a adotar as TICs de maneira significativa.

A Unesco, por meio do "Programa para uma informação justa e livre" também possui a adesão de vários países e organizações, visando ao desenvolvimento de estratégias e políticas para a viabilização do acesso à informação de domínio público. Outras de suas políticas dizem respeito à "[...] formação do usuário nas novas tecnologias de informação, o desenvolvimento de políticas de informação e promoção do sistema de redes locais e internacionais" (Felicié Soto, 2006, p.69, tradução do autor).

É preciso, porém, que as esferas envolvidas na reformulação de políticas de inclusão digital, principalmente em países como ĺndia e Brasil ${ }^{2}$ onde há grandes concentrações de renda, alto nível de desigualdade e um leque de iniciativas visando à inclusão social/digital, tenham metas e objetivos claros, específicos e regularmente revistos na agenda mundial.

\section{América Latina}

A situação latino-americana, quanto à sociedade da informação e inclusão digital, é variada. Destacaram-se a seguir "algumas" considerações em "alguns" países da região como Argentina, Bolívia, Republica Dominicana, México, Equador e Costa Rica. Para aprofundar tais informações, sugere-se o Relatório ${ }^{3}$ que analisou esses países.
Os problemas políticos de cunho geral submetidos à Argentina, mais intensamente na primeira metade desta década, levaram o país a desarticular seu contrato social e intensificar seus índices de pobreza. Tal situação levou à redefinição tanto do debate sobre as políticas quanto da sociedade da informação, assim como das questões ligadas à inclusão digital, com um enfoque mais direcionado para as $\mathrm{ONG}$.

A Bolívia, embora considerasse prioritárias as questões ligadas à comunicação, atentou, como um de seus pontos prioritários, para o fortalecimento da identidade, entendendo que as TIC teriam que ser apropriadas pela comunidade e corroborar com a produção de conteúdos locais, convergindo tecnologias novas e tradicionais (O Outro..., 2003).

Na Republica Dominicana, o leque de iniciativas estava orientado basicamente para garantir acesso à infraestrutura e total ausência de aspectos metodológicos para execução dos programas. Em 2003 - menciona Betancourt em O Outro lado do abismo o cenário nesse País revelava falta de estratégias quanto à apropriação das TIC como ferramenta para o desenvolvimento, e sequer se referia à capacitação enfocada na geração de conhecimento.

No caso mexicano, o debate de inserção na sociedade da informação se deu considerando os mecanismos e demandas civis, graças a sua experiência com processos organizativos. No México havia a intenção de utilização das TIC para busca de dispositivos que ampliassem o poder democrático e maior participação de atores - como governo, acadêmicos e ONG - no debate de inclusão de forma mais estruturada.

Equador apresentava como principal desafio criar um debate social em torno das TIC que não se limitasse somente à infraestrutura.

No caso da Costa Rica, as iniciativas e reflexões voltaram-se à sociedade do conhecimento (O Outro..., 2003). Embora o País contasse com uma das maiores indústrias de software da América Latina, em 2003, ainda não contava com um debate maduro nessa linha. A Costa Rica, no âmbito da Conferencia Internacional sobre a Economia do Conhecimento, enfatizou a necessidade de preparar condições de interação entre

2 Ver também experiências brasileiras em Vivafavela: une expérience brésilienne de l'accès numérique pour lutter contre la pauvreté.

$3 \bigcirc$ Relatório completo se encontra disponível em: <http://.lac.derechos.apc.org >. 
as empresas nacionais e as multinacionais. Dessa forma, sua inserção na sociedade do conhecimento estava direcionada à implementação de infraestrutura para desenvolvimento econômico (O Outro..., 2003).

As duas iniciativas que tratam no seu cerne da exclusão/inclusão digital, assinaladas no contexto mundial (CUMBRE e Unesco), possuem significância por abarcarem muitos países da América Latina. Entretanto faz-se essencial citar a contribuição da CEPAL no contexto da sociedade da informação, em parceria com as Nações Unidas por meio das iniciativas E-LAC e OsiLAC.

Programa da Sociedade da Informação da CEPAL teve inicio a partir de 1999, adotando uma linha de coesão social dentro dos moldes da União Européia. Teve seu marco no diálogo político e regulatório respaldado na Aliança para a Sociedade da Informação, no programa de Cooperação Europa/América Latina sobre a Sociedade da Informação (@LIS) e no Instituto para a Conectividade nas Américas (ICA).

Analisando brevemente o histórico do Observatório para a Sociedade da Informação da América Latina (OSILAC), verifica-se que se trata de uma iniciativa bastante direcionada para a questão estrutural da informação relacionada à tecnologia no contexto da sociedade da informação. A intenção primaz paira na quantificação para criação de bases estatísticas e indicadores, visando medir a sociedade da informação.

A Estratégia para a Sociedade da Informação na América Latina e o Caribe (ELAC) possui uma proposta baseada em metas que concebem as TICs como instrumentos de desenvolvimento econômico e inclusão social. A ELAC está alicerçada em um plano regional que, além de propiciar aspectos tecnológicos e de coesão social, também se preocupa com as indústrias de conteúdo digital, segundo Saadia Sanchéz ${ }^{4}$. Os planos de trabalho para o e-LAC2010 abarcam conteúdos digitais interativos, financiamento, gênero, governança da internet, governo eletrônico, indústrias criativas e conteúdo, infraestrutura, marco legal, resíduos tecnológicos, saúde eletrônica, estudos de softwares, teletrabalho e sobre TIC e descapacidade.

Dessa forma, as principais iniciativas desenvolvidas para atuarem em âmbito regional trabalham com uma perspectiva de sociedade da informação voltada à coesão social. Observa-se também que a inserção de pesquisadores - a exemplo de Emir Suaiden e Cosette Castro, que possuem uma linha preocupada com a transmissão de conteúdos, nos grupos de trabalho que as compõem constitui-se um estímulo para o debate acerca das políticas de inclusão no contexto regional.

Outras ênfases, contudo, foram adicionadas ao debate de inclusão social no continente e, em certa medida, impacta no direcionamento da infoinclusão, como o conceito de coesão social. Tal conceito é observado de maneira comparativa inevitável com outras sociedades européias e norte-americanas.

A idéia de coesão social que domina o debate internacional foi elaborada pela União Européia a partir dos anos 90 "[...] como parte de um discurso político e possui um sentido basicamente normativo-evocativo, que busca definir um horizonte desejável para a sociedade [...] sintetiza de certa forma os valores de solidariedade e igualdade [...]" de acordo com Sorj e Martuccelli (2008). Os autores chamam atenção para que no âmbito social a inserção do conceito em topografia tão diversa pode trazer efeitos que não podem ser generalizados. Assim também o é na inclusão digital, constituindo uma equivalente tarefa difícil a ser executada, como prescreveram os autores em $\bigcirc$ desafio latino-americano.

Como o continente deve cerca de US $\$ 726$ bilhões às instituições financeiras internacionais, as TIC estão condicionadas, na origem das políticas, a serem utilizadas como ferramentas para negócios ou divertimento para ricos (Inclusão..., 2003). Não é de se admirar que a penetração da internet não esteja, prioritariamente, direcionada a apropriação da informação por meio da tecnologia, com viés para fatores de competência e educação.

\section{Programa sociedade da informação: Brasil}

A oficialização da inserção do Brasil nesse novo contexto que envolve necessidade de participação mais ofensiva na ordem mundial contemporânea, considerando um caráter de inclusão, foi o Programa Sociedade da Informação (SOCINFO), registrado no

\footnotetext{
4 Diretora da Rede de Informação e Conhecimento e da Secretaria Permanente do Sistema Econômico Latino Americano e do Caribe (SELA), em entrevista realizada em Brasília em 2008 para a autoria deste artigo. $\bigcirc$ trecho de sua fala foi traduzido livremente.
} 
Livro Verde por meio do Decreto 3.294 de 15 de dezembro de 1999, em Brasília, cuja finalidade substantiva é:

[...] alcançar os alicerces de um projeto estratégico, de amplitude nacional, para integrar e coordenar o desenvolvimento e a utilização de serviços avançados de computação, comunicação e informação e de suas aplicações na sociedade (Brasil, 2000, p.5).

Segundo seus divulgadores, em apresentação nos eventos de divulgação, as linhas de ação do Programa visavam a: mercado, trabalho e oportunidades; universalização de serviços; educação para a sociedade da informação; conteúdos e identidade cultural; governo ao alcance de todos; tecnologiaschave e aplicações; e infraestrutura avançada. Seu conjunto de ações visava à socialização da informação e democratização do acesso à tecnologia. Para tanto, previa investimentos em bilhões para favorecer a implementação de uma malha de infraestrutura. Ainda fazem parte desse mesmo escopo de quesitos, e que mais se relaciona com o tema abordado neste estudo, a universalização do acesso (combatendo desigualdades e promovendo a cidadania) e a educação e aprendizado ao longo da vida (desenvolvendo competência).

A universalização do acesso constituiu um "grande guarda-chuva" de ações complexas, conforme os pontos de destaque relatados a seguir:

- todas as cidades de faixa de renda baixa teriam acesso à internet em curto prazo;

- equipamento projetado, fabricado e evoluído no Brasil; possibilidade de marcas;

- apropriação de ciclo de inovação tecnológica;

- serviços do governo disponível em rede unificada e interoperável.

A partir de uma breve análise dos pontos destacados, após quase 10 anos do lançamento do programa, percebe-se que a almejada "ágora digital" parece distanciar-se graças à brecha que se agrava, associada a outros aspectos inerentes à globalização como sociais, econômicos, políticos e culturais. Parcelas da população, sobretudo nas cidades de renda baixa, driblam esse cenário nas estatísticas, acessando internet por meio de lan house. Segundo o Comitê Gestor da
Internet no Brasil, em 2008, 47\% da população urbana acessou a internet pela lan house. Na área rural, o número é mais expressivo, (58\%). O fenômeno das lan hauses é proeminente em famílias pobres e de menor grau de instrução. Segundo Jambeiro (2008, p. 102), embora, "sem banda larga, os dados mostram que os habitantes de numerosos municípios passaram a poder interagir, via acesso discado, instantânea e virtualmente, com áreas deles distantes, em atividades de natureza tanto econômica quanto cultural, política e social".

Quanto ao ponto equipamentos projetados no Brasil e ciclo de inovação tecnológica, é possível ser observado na Avaliação das Políticas de Incentivo à P\&D e Inovação Tecnológica no Brasil, desenvolvida pelo IPEA em julho de 2009. Analisando a segunda metade da década do ano 2000, o IPEA observa que

[...] as atividades de Pesquisa e Desenvolvimento (P\&D) nacional têm uma agenda defasada de pesquisa, ainda pouco estruturada e já fora do foco da disputa tecnológica. Nesse caso há amplas diferenças entre a matriz de C\&T brasileira, a mundial e a dos países tecnologicamente emergentes, como Coréia e China (Instituto..., 2009).

Nesse contexto, o modelo brasileiro difere do padrão mundial concentrado nas áreas tecnológicas como Tecnologia da Informação (TI), Biotecnologia e Eletrônica, visto que na corrida tecnológica, o Brasil nem avançou nem retrocedeu. Especificamente no setor de inovação o país avançou a partir de 2003 com relação aos países da América Latina (Instituto..., 2009).

A accountability no Brasil, de maneira geral, implica a necessidade de levantar os atos públicos de forma a clarificar os processos de tomada de decisão. Dessa forma, a meta que previa uma rede unificada entre governos e sociedade carece de ampliação e engajamento por parte de ambos.

Segundo Suaiden, o primeiro momento do Programa Sociedade da Informação foi muito bom para elevar, extraordinariamente, a questão do custo do Brasil: "o Governo anterior, o primeiro mandato de FHC, entendeu Sociedade da Informação como informatização da sociedade". Projetos para enviar computadores para as escolas foram criados sem levar em consideração a alfabetização. O "[...] MEC já fazia isso com o livro sem antes criar o público leitor." Isso foi um erro crônico. 
Quando as TICs são consideradas somente como ferramentas para acessar a informação e se comunicar melhor, assume-se um concepção instrumental, concordando com Echeverría (2008): "Cuando se piensa de esta manera, se asume una concepción instrumental de las tecnologías, que a nuestro modo de ver resulta insuficiente para entender el profundo cambio social que las TIC posibilitan".

Vale ressaltar que o quinto objetivo do Livro Verde versa que a educação e aprendizado ao longo da vida desenvolvem competência (Brasil, 2000). Entretanto, ao que parece, a questão que envolve os recursos físicos (equipamentos e conectividade) foi mais considerada pelas políticas de informação brasileiras. Assim, esse objetivo, que trata do aprendizado "em e para" a tecnologia, está em vias de discussão. Suaiden acrescenta que "[...] hoje os países que tiveram êxito em acabar com a exclusão social implantaram um programa de inclusão que não era só baseado no computador". A capacitação, as metodologias que envolvem a importância da mediação da informação para acesso ao conteúdo, a competência informacional e alfabetização da informação são elementos que foram pouco privilegiados para viabilização do quinto objetivo.

Assim como as bibliotecas públicas brasileiras que avançam e recuam dependendo da gestão (Ferreira, 2006), os aparatos de inclusão digital entendem seu contexto efetivo, no âmbito das políticas públicas, como informação ou informatização, dependendo da política (politics) que o Estado exerce no momento. De acordo com Demo, as propostas dominantes de inclusão digital (tipo laboratório de informática, distribuição de computadores, cursinhos de digitalização etc.), não garantem nenhuma "inclusão" substancial; no fundo, é inclusão marginal, coisa pobre para o pobre.

Os mapeamentos da inclusão digital: ferramentas da segunda etapa da SOCINFO

No inicio da segunda metade dos anos 2000, outra ação governamental ganha notoriedade no Brasil: são os chamados mapeamentos ou observatórios. Acredita-se que esses mapeamentos funcionam como uma observação territorial das ações originadas do Livro
Verde, que propunha a "mão do Estado" para viabilização de inclusão digital e infraestrutura nacional para o trânsito de conteúdos digitais com objetivos estreitos voltados para as políticas de desenvolvimento pautado na competitividade de mercados, sobretudo o global.

Os mapeamentos têm sido uma abordagem constante de grandes instituições de pesquisa, visando a um traçado quantitativo dos programas, projetos $\mathrm{e}$ iniciativas que possuem proposta de inclusão digital. Muitos desses mapas possuem o apoio do Estado e/ou são institucionalizados por ele, como no caso do observatório nacional.

O Mapa da Inclusão Digital (MID) é uma iniciativa do Instituto Brasileiro de Informação Ciência e Tecnologia (IBICT). Trata-se de um projeto que visa efetuar o mapeamento de programas e pilotos de inclusão digital além de seus respectivos pontos de acesso com iniciativas públicas e privadas. Sua pretensão é abarcar todo território nacional, mensurando os avanços contra a exclusão digital no Brasil.

O Projeto foi dividido em duas etapas. Segundo Cecília Leite ${ }^{5}$, juntamente com Emir Suaiden, coordenadores do Projeto, a primeira etapa inclui dados potenciais enviados pelos programas/projetos e que necessitam de confirmação por parte das pontas (os próprios PID). De acordo com Carolina Lucena ${ }^{6}$, a dimensão quantitativa, apresentada nessa primeira etapa da pesquisa, serviu para suscitar a discussão do que vem a ser inclusão digital, qual dos conceitos seriam usados ou se não seria a ocasião de desenvolver novos paradigmas devido à complexidade das iniciativas mapeadas. Entretanto, no primeiro momento, a definição de pontos de inclusão digital utilizada pelo MID consiste em:

Pontos de inclusão digital (PIDs), também denominados telecentros, são locais dotados de computadores para acesso público à internet, ou apenas para treinamento em informática (Instituto..., 2009, p.7).

Lucena explicou a definição dizendo que "[...] neste primeiro momento não incluímos lanhouses,

\footnotetext{
${ }^{5}$ Coordenadora-geral do Programa de Inclusão Social, entrevistada em 28 de junho de 2007 no IBICT, Brasília, para a autoria deste artigo.

- Representante da Equipe do MID, entrevistada em 28 de junho de 2007, em Brasília (DF).
} 
porém incluímos o 'Mac Internet' que [...] tem uma característica muito similar à da lanhouse". Lucena em entrevista comentou que estão pensando na possibilidade de incluir, também, as lanhouses na segunda etapa que teria uma abordagem mais qualitativa, se levada em consideração uma nova visão que eles estão constatando: "Tudo que te faz sair de um estado para um outro, pode ser considerado inclusão digital".

Assim, o IBICT se propõe a contatar os PID de maneira mais direta, visando dar uma abordagem mais qualitativa por meio da atualização e validação dos dados. O MID conta com a cooperação do projeto Novos Brasis (em 2005) da Ol Telecomunicações e, atualmente, com a participação da Unesco.

O Mapa da Exclusão Digital desenvolvido pela FGV, além de procurar levantar dados das cidades mais excluídas, também comparou-os com os municípios mais incluídos, dividindo por regiões. Esse mapa proporcionou a possibilidade de categorizar as regiões e cidades mais desenvolvidas, assim como as que menos apresentam graus de inclusão nesse sentido. Os números desse mapeamento, pelo menos na Bahia, estão ligados ao desenvolvimento regional e econômico, o que nos leva a acreditar que seu resultado é condicionado ao PIB do município, levantado em outras instituições estatísticas como SEl e/ou IBGE.

Por fim, o Observatório Nacional da Inclusão Digital (ONID), que desenvolve um amplo levantamento das iniciativas da inclusão digital, apresenta categorização muito completa no que concerne à quantidade de informações mapeadas, possibilitando um mapa visual disponível na internet. O ONID coleta dados e aceita a indicação por meio de um cadastro em sua base de dados que alimenta o mapa. Sua política respalda-se no mapeamento nacional de iniciativas públicas, que são caracterizadas pelo âmbito de articulação e abrangência do principal mantenedor do programa, podendo ser denominadas como locais, estaduais, nacionais.

Em 2003, o Plano de Negócios com apoio do Ministério da Cultura lançou Inclusão digital: com a palavra a sociedade, onde apresentava o elenco de iniciativas, as quais se achou conveniente separar por eixos esquematizados no Quadro 1.

Como em vários outros contextos, ainda aqui é possível observar que a maioria das iniciativas concentra-se no eixo Rio/São Paulo, característica que perduraria nos dias atuais também na inclusão digital.

Assim, no caso brasileiro, vários atores abraçaram o debate da inclusão digital como prérequisito para a disponibilização de infraestrutura. Muitas vezes viram-se coalizões entre atores públicos e privados, como ONG e Estado, ou Estado e universidades. São perceptíveis, tanto na literatura institucional como na produção acadêmica, relatos que remetiam como principais barreiras à inclusão digital o preço dos computadores e softwares, disponibilidade e custo de conexões e de provedores de serviço. Entretanto, a partir da segunda metade desta década, o debate começou a sinalizar que os fatores educacionais e culturais eram relevantes barreiras, além de que esses fatores associados à concentração de renda e ao baixo poder aquisitivo constituíam obstáculos cruciais à inserção de fato na sociedade da informação pelo viés da inclusão digital.

\section{A inserção da Bahia na sociedade da informação}

O programa Sociedade da Informação também contou com lançamentos nas principais capitais do Brasil. Na Bahia, ocorreram algumas reuniões e encontros de lançamento do Livro Verde. Salvador foi a segunda cidade a receber o evento do livro, promovido pelo Ministério da Ciência e Tecnologia (MCT), que teve um foco mais voltado à comunidade acadêmica, embora não excluísse os interessados da comunidade.

$\bigcirc$ primeiro encontro de lançamento foi na Fundação Luís Eduardo Magalhães, em $1^{\circ}$ de fevereiro de 2001, com a presença do Ministro da Ciência e Tecnologia, Ronaldo Mota Sardenberg, governador César Borges e do secretário do Planejamento, Ciência e Tecnologia, Luiz Carreira. Também o coordenador geral do Programa - Tadao Takahashi, que definiu a SOCINFO como uma nova forma de "[...] organização social, em que a informação desempenha um papel central na atividade econômica e na qualidade de vida dos cidadãos" (Gazeta..., 2003).

Nos debates, as discussões giravam em torno da disposição de infraestrutura e muito se comentava sobre inclusão digital7. Entretanto, comentários naquele

\footnotetext{
7 Estudantes de Biblioteconomia foram convidados a participarem do lançamento e da série de debates na Fundação Luís Eduardo
} Magalhães (FLEM). Dessa forma, esse comentário é baseado nos blocos de anotações provenientes daquela ocasião. 
Quadro 1. Iniciativas para a inclusão digital.

\begin{tabular}{|c|c|c|c|c|}
\hline \multicolumn{2}{|c|}{ Iniciativas } & \multicolumn{3}{|c|}{ Eixos de Ação } \\
\hline Governo Federal & Sociedade Civil & Políticas Públicas & Educação & Conteúdo \\
\hline Gesac - Fome Zero & $\begin{array}{l}\text { Escolas de } \\
\text { informática e } \\
\text { cidadania - CDI }\end{array}$ & Telecentros SP & Proinfo (DF) & Sampa.org (SP) \\
\hline $\begin{array}{l}\text { Telecentros de } \\
\text { Negócios }\end{array}$ & Kindlink Brasil & Acessa SP & EducaRede & Escola do Futuro \\
\hline \multirow[t]{14}{*}{$\begin{array}{l}\text { Espaço Serpro } \\
\text { Cidadão }\end{array}$} & Viva Favela (RJ) & $\begin{array}{l}\text { Telecentros Porto } \\
\text { Alegre (RS) }\end{array}$ & $\begin{array}{l}\text { Informática } \\
\text { Pedagógica (SP) }\end{array}$ & RITS \\
\hline & Estação Futuro (RJ) & Cidadão Digital (RS) & $\begin{array}{l}\text { Rede de Telecentro } \\
(\mathrm{MG})\end{array}$ & $\begin{array}{l}\text { Cidade do } \\
\text { Conhecimento }\end{array}$ \\
\hline & Rede Saci (SP) & $\begin{array}{l}\text { Digitando o Futuro } \\
\text { (PN) }\end{array}$ & $\begin{array}{l}\text { Internet nas Escolas } \\
(M G)\end{array}$ & $\begin{array}{l}\text { Biblioteca Digital } \\
\text { Multimídia }\end{array}$ \\
\hline & $\begin{array}{l}\text { Garagem Digital } \\
\text { (SP) }\end{array}$ & Paranavegar (PR) & Sua Escola & \\
\hline & $\begin{array}{l}\text { Centro Sócio- } \\
\text { Pastoral N.S. da } \\
\text { Conceição (RN) }\end{array}$ & Liberdade Digital (RJ) & Telemar Educação & \\
\hline & Rede Cipó (BA) & $\begin{array}{l}\text { Programa para o } \\
\text { Futuro (PE) }\end{array}$ & Escola Digital (DF) & \\
\hline & Internet Livre (SP) & Ilhas Digitais (CE) & Escol@Virtual & \\
\hline & Rede Cyberela & Solonópole (CE) & $\begin{array}{l}\text { Educação para o } \\
\text { Futuro }\end{array}$ & \\
\hline & Kabum (RJ) & $\begin{array}{l}\text { Cidade do } \\
\text { Conecimento (TO) }\end{array}$ & KidSmart & \\
\hline & $\begin{array}{l}\text { Educar para Crescer } \\
\text { (SP) }\end{array}$ & Topawa (AM) & N@Escola (SP) & \\
\hline & $\begin{array}{l}\text { Consulado da } \\
\text { Mulher (SP) }\end{array}$ & Navegar (AP) & Café Digital (SP) & \\
\hline & $\begin{array}{l}\text { Computação } \\
\text { Solidária (SP) }\end{array}$ & & & \\
\hline & Intel Clubhouse (SP) & & & \\
\hline & $\begin{array}{l}\text { Espaços de } \\
\text { Informática e } \\
\text { Cidadania (SP) }\end{array}$ & & & \\
\hline
\end{tabular}

Nota: Os que não indicam a unidade federativa são considerados nacionais.

Fonte: Baseado no livro Inclusão digital com a palavra, a sociedade (2003).

吕 
primeiro momento eram exclusivamente voltados aos aspectos da infraestrutura tecnológica do estado, o que era essencial e pertinente na ocasião, embora seu quinto objetivo trate de aprendizagem e educação por meio dessas tecnologias.

Houve ainda um segundo lançamento do livro na capital baiana, no dia 14 de julho do mesmo ano, na 53 ${ }^{a}$ Reunião Anual da Sociedade Brasileira para o Progresso da Ciência (SBPC). Naquele contexto, maciçamente formado por grupos de acadêmicos presentes na Reunião, o foco foi mais voltado à análise e discussão de propostas, visando fornecer subsídios aos empresários e cientistas que formavam a comissão do livro.

governo baiano abraçou definitivamente a questão da inclusão digital em finais da primeira metade desta década, sendo uma preocupação mais oficial por parte da Secretaria de Ciência, Tecnologia e Inovação do estado da Bahia (SECTI). A SECTI foi criada em 2003, como Secretaria extraordinária, sendo instituída como ordinária em janeiro de $2004^{8}$. Essa Secretária de Estado instituiu uma política baseada em tecnologia da informação e inovação, tendo como uma de suas linhas de ação a inclusão sócio-digital, criando o Programa de Inclusão Sócio Digital (PISD). Mais tarde, coincidindo com a mudança partidária no poder do estado, passou a denominar-se Cidadania Digital. Sendo reconhecido como o principal programa de inclusão sócio-digital da Bahia, suas linhas de ação são basicamente baseadas no fornecimento de infraestrutura (quatro mil computadores; $518 \mathrm{mil}$ usuários; 268 municípios atendidos; 364 Centros de Digitais de Cidadania (CDC) instalados. Toda a infraestrutura de sistema é baseada em software livre, e previa uma ampliação até o final de 2008 com 900 CDC).

Em 2009 o estado da Bahia também passa a utilizar a metodologia de mapa, criando o Mapa Digital. Projetado pela SECTI, o mapa apresenta o "estado digital" com divisões baseadas nos Territórios de Identidade criados com o envolvimento do Ministério do Desenvolvimento Agrário e a Secretária de Desenvolvimento Territorial em 2003 e, mais tarde, em 2006, conduzidos pela SEPLAN, considerando os aspectos culturais da realidade local.
Diferente dos outros mapas já apresentados, não exerce sua coleta por meio dos cadastros realizados a partir da própria iniciativa. Executivos que coordenam a frente do Mapa migram informações fornecidas pelo próprio PISD.

Pode-se relatar que grande parte das informações entre os mapeamentos não convergem. Visando à localização de pontos de inclusão digital (PID) em 10 cidades baianas para uma pesquisa de inclusão digital, pôde-se observar que muitas das informações divergem entre os mapeamentos. Algumas vezes o ponto aparece no mapa da Bahia no ONID, mas não no Mapa Digital baiano, e vice-versa.

\section{CONSIDERAÇÕES FINAIS}

A globalização foi responsável por desenhar o conjunto da atual política de informação. Questões como disseminação da informação, consumo da informação, conteúdo, educação a distância, digital divide, accountability e governo eletrônico ilustram a política de informação no contexto global. O problema é que cada país a desenvolve de acordo com suas necessidades e, na maioria das vezes, de acordo com seus jogos de poder.

Na América Latina, as situações relativas às políticas públicas e de informação são variadas. Percebem-se iniciativas bem intencionadas, com interesses e objetivos, mas mais acordadas com as propostas da primeira etapa da Cúpula Mundial para Sociedade da Informação. A globalização responsabiliza- se, entretanto, por exportar da União Européia para a Região o conceito de coesão social. Assim como tantos outros, tal conceito também foi formulado por países mais avançados, tanto no plano tecnológico como no plano democrático. Por isso, tamanha importância em instituir o debate, visando observar este conceito no âmbito das políticas que pretendem a participação do cidadão na sociedade atual.

Embora a infraestrutura tenha, em parte, sido contornada pela informatização massiva proporcionada pelos aparatos do Programa Sociedade da Informação no Brasil, o lado inclusivo dessa ação se encontra débil.

8 Informação extraída do Painel TeleBrasil/Costa do Sauípe/2008 promovido pelo Governo da Bahia. 
No âmbito local, exemplificado neste artigo, percebe-se que, no segundo período da década de 2000 , houve uma expansão dos principais programas de inclusão digital. Muitos daqueles, no entanto, que não são tidos como os oficiais, entrarão em decadência, a exemplo do mantido pelo Liceu de Artes e Ofícios da Bahia e o do Instituto Fica (institucionalizado por grupos étnicos). Também os projetos ligados a Casa Brasil vêm apresentando dificuldades para atuarem no estado.

Com base nos fatos e na literatura do campo, acredita-se que a política de informação contemporânea nacional, embora seja um instrumento avançado de políticas públicas, e fortemente ligado aos atores internacionais, como ONU e UNESCO, continua focando na expansão da infraestrutura, o que tampouco descaracteriza a proposta mundial de inclusão digital. Entretanto novos elementos devem, também, fazer parte do debate na arena. Tópicos como inclusão digital e educação, inclusão digital e conteúdo, inclusão digital e recurso humano são prioridades que precisam ser consideradas ao lado das questões sobre banda larga e computadores para todos. Essas preocupações não foram superadas, a bem da verdade nenhuma delas, devendo figurar juntas na política de informação que visa à participação inclusiva digital tanto no conceito histórico de cidadania plena quanto no inédito conceito de coesão social.

\section{REFERÊNCIAS}

BAUMAN, Z. Modernidade liquida. Rio de Janeiro: Jorge Zahar, 2001.

BAUMAN, Z. Confiança e medo na cidade. Rio de Janeiro: Jorge Zahar, 2009.

BOBBIO, N. Estado, governo e sociedade: para uma teoria geral da políitica. 15. ed. São Paulo: Paz e Terra, 2009.

BOEKER, P.H. Latin America's turnaround: privatizations, foreign investmente, and growth. San Francisco: Institute for Comtemporary Studies, 1995.

BRASIL. Sociedade da informação: ciência e tecnologia para a construção da sociedade da informação no Brasil. Brasília, 2000.

BUENO SANCHÉZ, E. La herancia del siglo XX: información y globalización. In: MORALES CAMPOS, E. Infodiversidad y cibercultura: globalización e información en la América Latina. Buenos Aires: Alfagrama, 2008.

CUMBRE MUNDIAL SOBRE LA SOCIEDAD DE LA INFORMACIÓN (Ginebra). Compromiso de Túnez. Ginebra: CMSI, 2006. Disponível em: <http://www.itu.int/wsis/indexes.html>. Acesso em: 16 dez. 2009.

CUMBRE MUNDIAL SOBRE LA SOCIEDAD DE LA INFORMACIÓN. (Ginebra) Implementación de la CMSI por línea de acción. Ginebra: CMSI, 2009. Disponível em: <http:// www.itu.int/wsis/index-es.html>. Acesso em: 6 jan. 2010.

ECHEVERRÍA, J. Apropiación social de las tecnologías de la información y comunicación. Revista CTS, v.4, n. 10, 2008.

FELICIÉ SOTO, A.M. Biblioteca publica: sociedad de la información y brecha digital. Buenos Aires: Alfagrama Ediciones, 2008.

FERREIRA, M.M. Políticas públicas de informação e políticas culturais: e as bibliotecas públicas para onde vão? Transinformação, v. 18, n.2, 113-122, 2006.
GALEANO, E. As veias abertas da América Latina. Rio de Janeiro: Paz e Terra, 1978.

GAZETA MERCANTIL DA BAHIA. Livro Verde vai ser lançado amanhã. Salvador, 2003.

INCLUSÃO digital: com a palavra, a sociedade. São Paulo: Plano de Negócios, 2003.

INSTITUTO DE PESQUISA ECONÔMICA APLICADA. Avaliação das políticas de incentivo à $P \& D$ e inovação tecnológica no Brasil. 2009. Disponível em: < www.ipea.gov.br/sites/000/2/pdf/ Nota_Tecnica_julho20094.pdf>. Acesso em: 21 dez. 2009.

JAMBEIRO, O. Estado, cidades e políticas de comunicação. Revista Eco Pós, v. 1 1 , n. 1, 2008.

MARCIANO, J.L.P. Bases teóricas para a formulação de políticas de informação. Informação \& Sociedade, v. 16, n.2, p.37-50, 2006.

MILANI, C.R.S. Políticas públicas locais e participação na Bahia: o dilema gestão versus política. Sociologias, v. 8, n. 16, 2006.

O OUTRO lado do abismo: as perspectivas latino-americanas e do Caribe diante da CMSI. Caracas: Rede sobre o Impacto Social das Tecnologias da Informação e Comunicação, 2003.

RUA, M.G.; CARVALHO, M.I.V. Análise das políticas públicas: conceitos básicos. In: O ESTUDO da política: tópicos selecionados. Brasília: Paralelo 15, 1998.

SANCHEZ, O.A. O Poder burocrático e o controle da informação. [s.I]: BUFSCALegis, 2006.

SANTOS, M. O espaço do cidadão. 6. ed. São Paulo: Estudio Nobel, 2002.

SANTOS, M. Por uma outra globalização. Rio de Janeiro: Record, 2004.

SORJ, B.; MARTUCCELLI, D. O desafio latino-americano: coesão social e democracia. Rio de Janeiro: Civilização Brasileira, 2008. 